\title{
[ARTICLE]
}

\section{THE DEVELOPMENT OF THE DETERMINER SYSTEM IN THE HISTORY OF ENGLISH}

\author{
SEISHIROU IBARAKI \\ Nagoya University
}

\begin{abstract}
This paper attempts to clarify the development of the determiner system by examining the distribution of elements within noun phrases in the history of English, arguing that their word order patterns are basically the same in Present-day English and early English, except possessive pronouns, which have been grammaticalized into a central determiner. The unique behavior of possessive pronouns was responsible for a variety of word order patterns and the cooccurrence of articles/demonstratives and possessive pronouns in early English: the base-generated position of possessive pronouns was Spec-NumP in Old English and the head of NumP in Middle English and Early Modern English. Finally, grammaticalization of possessive pronouns in Late Modern English led to the establishment of the determiner system as in Present-day English.*
\end{abstract}

Keywords: determiner system, double determiner, grammaticalization, noun phrase, possessive pronoun

\section{Introduction $^{1}$}

This paper aims to explore the development of the determiner system by investigating the word order of elements within noun phrases in the history

* This is a revised version of the paper read at the 25th General Meeting of the Modern English Association held at Hiroshima Jogakuin University on May 23, 2008. I am grateful to two anonymous $E L$ reviewers for their helpful comments on an earlier version of this paper. I also gratefully acknowledge the valuable comments and suggestions of Masachiyo Amano, Tomoyuki Tanaka and all the members of the Department of English Linguistics, Nagoya University. All remaining errors and inadequacies are of course my own.

1 Here are the historical periods of English standardly assumed: Old English (OE: 4501100), Middle English (ME: 1100-1500), Early Modern English (EModE: 1500-1700), Late Modern English (LModE: 1700-1900), and Present-day English (PE: 1900-). This paper also uses the term "early English" to refer to all the early stages of English except PE. 
of English. ${ }^{2}$ In the tradition of English grammar, the determiner system in $\mathrm{PE}$ has been characterized by dividing determiners into the following three classes.

Table 1

\begin{tabular}{ll}
\hline Predeterminer: & e.g. all, both, half \\
Central determiner: & $\begin{array}{l}\text { e.g. articles, demonstratives, } \\
\text { possessive pronouns, any, every, some }\end{array}$ \\
Postdeterminer: & e.g. cardinal and ordinal numerals, few, many \\
\hline
\end{tabular}

(cf. Quirk et al. (1985: 253))

Quirk et al. (1985) state that the three classes of determiners are distinguished on the basis of their positions in relation to one another, and adjectives appear between determiners and the head noun within noun phrases. Thus, the positions of elements within noun phrases such as articles, demonstratives, possessive pronouns, quantifiers, adjectives and so on are fixed in PE, and some of them are not allowed to cooccur within the same noun phrase. As illustrated in (1), the word order of the three classes of determiners is rigid: predeterminers precede central determiners, which in turn precede postdeterminers. Moreover, the examples in (2) show that adjectives must follow all the classes of determiners, and articles, demonstratives and possessive pronouns cannot cooccur within the same noun phrase.

(1) a. *those all trouble (cf. all those trouble)

b. *five the all boys (cf. all the five boys)

c. *two both students (cf. both two students)

(cf. Quirk et al. (1985: 253))

(2) a. * good the king (cf. the good king)

b. *old my friends (cf. my old friends)

c. *that his book / *his that book

It has often been said that the word order in early English was rather free because of the rich system of case endings and other inflectional morphology, so word order patterns like (1) and (2) were once possible. A related question is whether the determiner system in early English was different

2 Our focus here is on prenominal elements, excluding postnominal elements. Genitive full noun phrases are also beyond the scope of this paper, because they have undergone a complex path of development and deserve to be discussed in an independent paper (Allen (2003)). But this paper deals with possessive pronouns, which are usually included in the determiner system and show an interesting change in the history of English. 
from that in PE, and if so, how different it is between PE and early English.

As for the development of the determiner system, there have been some studies arguing that there was no functional category D in early English, and that it was introduced at some time in the history of English (Yamamoto (1989) and Osawa (2000)). For the word order of elements within noun phrases in early English, some linguists argue that they were free to appear in any position within noun phrases (Carlson (1978), Lightfoot (1979) and Yamamoto (1989)), while others argue that they exhibit several word order patterns, with the implication that their positions within noun phrases were fixed to some extent (Mitchell (1985) and Alexiadou (2004)). Based on these arguments, it might be assumed that in early English, the word order of elements within noun phrases was free, or at least, they showed freer distribution than in PE. As we will see, however, there is empirical evidence to argue against this widely accepted assumption: the data collected from historical corpora suggest that the distribution of elements within noun phrases in early English was basically the same as in PE, except that of possessive pronouns.

The purpose of this paper is to provide a systematic investigation of the distribution of elements within noun phrases, namely quantifiers, articles/ demonstratives, possessive pronouns and adjectives, in the history of English, and to account for the development of the determiner system within the framework of generative grammar. The results of this investigation will show that the word order of elements within noun phrases was almost fixed in early English; the key difference between PE and early English is whether or not articles/demonstratives and possessive pronouns can cooccur within the same noun phrase. The fact that they do not cooccur in PE suggests that possessive pronouns compete with articles/demonstratives for the same position in noun phrases, which was not the case in early English. This difference is argued to be closely related to the grammaticalization of possessive pronouns into a central determiner.

The organization of this paper is as follows. Section 2 presents the data on the distribution of elements within noun phrases, which have been collected from The York-Toronto-Helsinki Parsed Corpus of Old English (henceforth, YCOE), The Second Edition of the Penn-Helsinki Parsed Corpus of Middle English (henceforth, PPCME2), The Penn-Helsinki Parsed Corpus of Early Modern English (henceforth, PPCEME) and The Collins Wordbanks Online (henceforth, Collins). This reveals that the syntactic status of possessive pronouns in early English was different from that in 
PE. Section 3 briefly reviews some previous studies on the distribution of elements within noun phrases in early English, pointing out their problems. Section 4 attempts to account for the change in the distribution of possessive pronouns in the history of English. Section 5 is the conclusion of this paper.

\section{Data}

This section investigates the distribution of quantifiers, articles/demonstratives, possessive pronouns and adjectives within noun phrases by making use of the four corpora just mentioned. It will be found that their behavior in early English was basically the same as in PE, except that of possessive pronouns.

\subsection{Quantifiers}

This section focuses on the behavior of quantifiers, all, both, half, every, any, some, many and few. As discussed above, these quantifiers can be classified as follows in terms of their positions within noun phrases.

Table 2

\begin{tabular}{ll}
\hline Predeterminer & $:$ all, both, half \\
Central determiner & : every, any, some \\
Postdeterminer & $:$ many, few \\
\hline
\end{tabular}

The word order patterns to be examined in YCOE, PPCME2, PPCEME and Collins are given in (3).

(3) a. Q - Art/Dem - N

b. Art/Dem - Q - N

$\mathrm{Q}=$ quantifier, Art/Dem $=$ article or demonstrative, $\mathrm{N}=$ noun

As shown in (3), we investigate the positions of quantifiers in relation to articles/ demonstratives which are classified as central determiners. Note that possessive pronouns are excluded in (3) because they did not behave as a central determiner in early English, as we will see in section 2.2. Moreover, it is generally assumed that articles did not exist in OE (the definite article later developed from demonstratives and the indefinite article from the numeral one; Fischer and Wurff (2006: 116)), so the relevant data in OE only involve demonstratives as elements of Art/Dem.

First, let us consider how the predeterminers, all, both and half, are positioned within noun phrases. The results of the investigation based on the 
four corpora are shown in Table 3.

Table 3

\begin{tabular}{|c|c|c|c|}
\hline ALL & All - Art/Dem - N & Art/Dem - All - N & Total \\
\hline YCOE & $1927(99.85 \%)$ & $3(0.15 \%)$ & 1930 \\
\hline PPCME2 & $2056(100 \%)$ & $0(0 \%)$ & 2056 \\
\hline PPCEME & $2048(100 \%)$ & $0(0 \%)$ & 2048 \\
\hline Collins & $21014(99.94 \%)$ & $13(0.06 \%)$ & 21027 \\
\hline \hline BOTH & Both - Art/Dem - N & Art/Dem - Both - N & Total \\
\hline YCOE & $9(100 \%)$ & $0(0 \%)$ & 9 \\
\hline PPCME2 & $11(100 \%)$ & $0(0 \%)$ & 11 \\
\hline PPCEME & $69(97.18 \%)$ & $2(2.82 \%)$ & 71 \\
\hline Collins & $1795(99.67 \%)$ & $6(0.33 \%)$ & 1801 \\
\hline \hline HALF & Half - Art/Dem - N & Art/Dem - Half - N & Total \\
\hline YCOE & $11(52.38 \%)$ & $10(47.62 \%)$ & 21 \\
\hline PPCME2 & $37(80.43 \%)$ & $9(19.57 \%)$ & 46 \\
\hline PPCEME & $173(83.57 \%)$ & $34(16.43 \%)$ & 207 \\
\hline Collins & $3926(59.71 \%)$ & $2649(40.29 \%)$ & 6575 \\
\hline
\end{tabular}

It is observed from Table 3 that the distribution of all and both in YCOE, PPCME2, PPCEME, and Collins shows a strong tendency for them to precede central determiners within noun phrases. As for these two quantifiers, there seems to be no difference in their distribution among OE, ME, EModE and PE: they have been predeterminers throughout the history of English.

However, an interesting difference is observed between the distribution of all and both, on the one hand, and that of half, on the other: in contrast to all and both, half can be used as a postdeterminer as well as a predeterminer. In this respect, the ratio of the predeterminer use to the postdeterminer use of half is similar between PE and early English, though it seems that the predeterminer use was predominant in ME and EModE. Alongside all and both, half is generally classified as a predeterminer in PE (Quirk et al. (1985: 253)), but Table 3 indicates that it is also frequently used as a postdeterminer in PE. Given the results in Table 3, it is reasonable to assume that half has been used both as a predeterminer and as a postdeterminer since the OE period. ${ }^{3}$

3 Amano (2007) argues that half is being grammaticalized into a postdeterminer in PE. 
Second, the distribution of the central determiners, every, ${ }^{4}$ any and some in the historical corpora is also basically the same as that observed in PE, as shown in Table 4.

Table 4

\begin{tabular}{|c|c|c|c|c|}
\hline EVERY & Every - Art/Dem - N & Art/Dem - Every - N & Every - N & Total \\
\hline YCOE & $0(-\%)$ & $0(-\%)$ & $0(-\%)$ & 0 \\
\hline PPCME2 & $0(0 \%)$ & $0(0 \%)$ & $214(100 \%)$ & 214 \\
\hline PPCEME & $4(0.33 \%)$ & $0(\%)$ & $1207(99.67 \%)$ & 1211 \\
\hline Collins & $2(0.01 \%)$ & $12(0.06 \%)$ & $20485(99.93 \%)$ & 20499 \\
\hline \hline ANY & Any - Art/Dem - N & Art/Dem - Any - N & Any - N & Total \\
\hline YCOE & $1(0.1 \%)$ & $0(0 \%)$ & $1007(99.9 \%)$ & 1008 \\
\hline PPCME2 & $0(0 \%)$ & $0(0 \%)$ & $987(100 \%)$ & 987 \\
\hline PPCEME & $54(1.12 \%)$ & $0(0 \%)$ & $4761(98.88 \%)$ & 4815 \\
\hline Collins & $20(0.06 \%)$ & $24(0.06 \%)$ & $35236(99.88 \%)$ & 35280 \\
\hline \hline SOME & Some - Art/Dem - N & Art/Dem - Some - N & Some - N & Total \\
\hline YCOE & $37(1.55 \%)$ & $0(0 \%)$ & $2357(98.45 \%)$ & 2394 \\
\hline PPCME2 & $0(0 \%)$ & $1(0.18 \%)$ & $557(99.82 \%)$ & 558 \\
\hline PPCEME & $1(0.04 \%)$ & $1(0.04 \%)$ & $2232(99.92 \%)$ & 2234 \\
\hline Collins & $70(0.17 \%)$ & $36(0.09 \%)$ & $41587(99.74 \%)$ & 41693 \\
\hline
\end{tabular}

In all the corpora, almost all of the attested examples fall into the Q-N pattern and there are few examples of the other two patterns. This suggests that every, any and some rarely occur with other central determiners throughout the history of English, indicating that they have been central determiners since the OE period.

Finally, let us examine the distribution of the postdeterminers, many and few, within noun phrases. Consider the results of the investigation based on the four corpora in Table 5.

${ }^{4}$ According to the Oxford English Dictionary, every first appeared around the end of the 12th century. Indeed, no examples of noun phrases with every are found in YCOE, as shown in Table 4. 
Table 5

\begin{tabular}{|c|c|c|c|}
\hline MANY & Many - Art/Dem - N & Art/Dem - Many - N & Total \\
\hline YCOE & $0(0 \%)$ & $9(100 \%)$ & 9 \\
\hline PPCME2 & $69(94.52 \%)$ & $4(5.48 \%)$ & 73 \\
\hline PPCEME & $36(59.02 \%)$ & $25(40.98 \%)$ & 61 \\
\hline Collins & $253(23.56 \%)$ & $821(76.44 \%)$ & 1074 \\
\hline \hline FEW & Few - Art/Dem - N & Art/Dem - Few - N & Total \\
\hline YCOE & $1(11.11 \%)$ & $8(88.89 \%)$ & 9 \\
\hline PPCME2 & $0(0 \%)$ & $24(100 \%)$ & 24 \\
\hline PPCEME & $0(0 \%)$ & $93(100 \%)$ & 93 \\
\hline Collins & $6(0.05 \%)$ & $12634(99.95 \%)$ & 12640 \\
\hline
\end{tabular}

The frequency of few preceding central determiners is very small, accounting for 1 among 9 examples in YCOE and 6 among 12640 examples in Collins, respectively. As for many, although 69 examples and 36 examples of Many-Art/Dem-N are attested in PPCME2 and PPCEME, respectively, almost all of these examples involve the indefinite article $a(n)$ : only one of the 36 examples attested in PPCEME involves the definite article the. Similarly, 253 examples of Many-Art/Dem-N are attested in Collins, but as many as 225 examples involve the indefinite article $a(n)$. Therefore, it seems to be the case that throughout the history of English, many can be used both as a predeterminer and as a postdeterminer, and the former use is almost restricted to examples in which it is followed by the indefinite article $a(n) .^{5}$

So far, we have observed the distribution of quantifiers which are classified into predeterminers, central determiners and postdeterminers in the history of English. What we have found is that at least for the kinds of quantifiers examined here, their distribution is basically the same in PE and early English. As will be discussed in section 3, this fact runs counter to the observations in previous studies that elements could be freely ordered within noun phrases in early English. On the contrary, the results of the investigation in this section suggest that the word order of quantifiers within noun

5 Alternatively, Huddleston (2002) suggests that many combines with the indefinite article to form a complex determiner in PE. Note that the fact that Many-Art/Dem-N is not found in YCOE is due to the absence of the indefinite article in OE; see Nakao (1972) for the observation that the indefinite article began to appear in the beginning of the 13th century. 
phrases has been fixed throughout the history of English, which will lead us to assume that the determiner system as in Table 1 was already established in $\mathrm{OE}$, at least for quantifiers.

\subsection{Articles/Demonstratives, Possessive Pronouns and Adjectives}

One of the most remarkable properties of noun phrases in early English is the cooccurrence of articles/demonstratives and possessive pronouns, constituting what are widely known as double determiners in the literature. According to Carlson (1978), Lightfoot (1979) and Yamamoto (1989), another property is that adjectives could precede articles/demonstratives and possessive pronouns in early English. This section investigates the distribution of articles/demonstratives, possessive pronouns and adjectives, in order to check the validity of these observations on noun phrases in early English.

First, let us examine whether adjectives could precede articles/demonstratives and possessive pronouns within noun phrases in early English. For this purpose, the word order patterns in (4) have been searched in YCOE, PPCME2 and PPCEME, yielding the results summarized in Table 6.

(4) a. Art/Dem - Adj - N

b. Adj - Art/Dem - N

c. Poss - Adj - N

d. Adj - Poss - N

Adj $=$ adjecitve, Poss $=$ possessive pronoun

Table 6

\begin{tabular}{|c|c|c|c|}
\hline & Art/Dem - Adj - N & Adj - Art/Dem - N & Total \\
\hline YCOE & $20306(99.65 \%)$ & $71(3.5 \%)$ & 20377 \\
\hline PPCME2 & $11928(98.79 \%)$ & $146(1.21 \%)$ & 12074 \\
\hline PPCEME & $24960(97.6 \%)$ & $613(2.4 \%)$ & 25573 \\
\hline & Poss - Adj - N & Adj - Poss - N & Total \\
\hline YCOE & $3055(99.16 \%)$ & $26(0.84 \%)$ & 3081 \\
\hline PPCME2 & $3103(99.97 \%)$ & $1(0.03 \%)$ & 3104 \\
\hline PPCEME & $5888(99.76 \%)$ & $14(0.24 \%)$ & 5902 \\
\hline
\end{tabular}

In OE, ME and EModE, the patterns Art/Dem-Adj-N and Poss-Adj-N are the overwhelming majority, whereas there are just a few examples of the patterns Adj-Art/Dem-N and Adj-Poss-N. Therefore, it is concluded that adjectives in early English behaved like those in PE, normally following ar- 
ticles/demonstratives and possessive pronouns. ${ }^{6}$

Next, consider the case of double determiners where articles/demonstratives and possessive pronouns cooccur within the same noun phrase. The word order patterns in (5) have been searched in YCOE, PPCME2 and PPCEME, yielding the results summarized in Table 7.

(5) a. Art/Dem - Poss - N

b. Poss - Art/Dem - N

Table 7

\begin{tabular}{|c|c|c|c|}
\hline & Art/Dem - Poss - N & Poss - Art/Dem - N & Total \\
\hline YCOE & $187(74.5 \%)$ & $64(25.5 \%)$ & 251 \\
\hline PPCME2 & $4(80 \%)$ & $1(20 \%)$ & 5 \\
\hline PPCEME & $129(100 \%)$ & $0(0 \%)$ & 129 \\
\hline
\end{tabular}

What is noticeable here is that the number of examples with the order Poss-Art/Dem-N drastically decreases in ME, and finally no examples are attested in EModE. The order Art/Dem-Poss-N, on the other hand, is still frequently observed in EModE, and it survived until the beginning of the 20th century (see section 4). An immediate question here is why the order Poss-Art/Dem-N disappeared in the history of English earlier than the order Art/Dem-Poss-N. This can be attributed to the unique behavior of possessive pronouns in the history of English, which will be discussed at length in section 4.

Finally, consider the more complicated cases where articles/demonstratives, possessive pronouns and adjectives cooccur within the same noun phrase. Since very few examples are attested in YCOE, PPCME2 and PPCEME where adjectives precede articles/demonstratives or possessive pronouns in the initial position of noun phrases (see Table 6), only the follow-

${ }^{6}$ If we take a close look at the relevant data, it is observed that the kinds of adjectives that precede articles/demonstratives and possessive pronouns are highly restricted. In YCOE, such adjectives are limited to two kinds: one is the adjective equivalent to middle in PE and the other includes some adjectives ending with -weard which express directions. The adjectives attested in the order Adj-Art/Dem-N in PPCME2 and PPCEME are also limited to two kinds: one is the adjective such and the other includes some adjectives modified by degree adverbs such as so and too. We will put aside these exceptional cases here, just noting that some particular property of the relevant kinds of adjectives would lead to their unusual positioning within noun phrases. See Matushansky (2002) for the analysis that such and adjectives modified by degree adverbs move to the initial position of noun phrases in PE. 
ing word order patterns have been examined.

(6) a. Art/Dem - Poss - Adj - N

b. Art/Dem - Adj - Poss - N

c. Poss - Art/Dem - Adj - N

d. Poss - Adj - Art/Dem - N

Table 8 shows the distribution of $(6 a, b)$ in the three corpora where articles/ demonstratives precede the other elements within noun phrases.

Table 8

\begin{tabular}{|c|c|c|c|}
\hline & Art/Dem - Poss - Adj - N & Art/Dem - Adj - Poss - N & Total \\
\hline YCOE & $18(45 \%)$ & $22(55 \%)$ & 40 \\
\hline PPCME2 & $1(50 \%)$ & $1(50 \%)$ & 2 \\
\hline PPCEME & $42(76.36 \%)$ & $13(23.64 \%)$ & 55 \\
\hline
\end{tabular}

It seems that adjectives may precede or follow possessive pronouns when they follow articles/demonstratives, which is interesting because adjectives cannot precede possessive pronouns in the absence of articles/demonstratives, as we saw in Table 6. Below I provide examples of each pattern.

(7) a. se heora halga bisceop the-Nom their holy-Nom bishop-Nom

(coblick,LS_25_[MichaelMor[BlHom_17]]:201.88.2578:02)

b. this my excellent remedy

(CLOWES-E2-P1,45.241:e2)

(8) a. pam ylcan his nefan the-Dat same-Dat his nephew-Dat

$$
\text { (cogregdC,GD_1_[C]:9.64.11.717:o2) }
$$

b. the honourable my verie good mother

(TBARRING-E2-P1,96.30:e2)

Table 9 shows the distribution of $(6 \mathrm{c}, \mathrm{d})$ in the three corpora where possessive pronouns are in the leftmost position within noun phrases, preceding articles/demonstratives and adjectives.

Table 9

\begin{tabular}{|c|c|c|c|}
\hline & Poss - Art/Dem - Adj - N & Poss - Adj - Art/Dem - N & Total \\
\hline YCOE & $241(100 \%)$ & $0(0 \%)$ & 241 \\
\hline PPCME2 & $0(0 \%)$ & $0(0 \%)$ & 0 \\
\hline PPCEME & $0(0 \%)$ & $0(0 \%)$ & 0 \\
\hline
\end{tabular}

We observed in Table 7 that only one example of the order Poss-Art/ Dem- $\mathrm{N}$ is attested in ME and there are no such examples in EModE. Ta- 
ble 9 shows that no examples are found in PPCME2 and PPCEME where possessive pronouns precede articles/demonstratives. However, it should be noticed that even in OE, the order Poss-Adj-Art/Dem-N is never attested, in contrast to as many as 241 examples of the order Poss-Art/DemAdj-N. Some of the latter examples are given in (9).

(9) a. his pone readan gim his that-Acc red-Acc jewel-Acc

b. min pæt unrote $\bmod$ (coblick,HomU_18_[BlHom_1]:9.125.121:o2) my that-Nom sad-Nom mind-Nom (cogregd,GDPref_and_3_[c]:33.243.3444:o2)

c. his pæt berhte leoht his that-Acc bright-Acc light-Acc

(comart3,Mart_5_[Kotzor]*Ma26,A.17.485:02)

\subsection{Summary}

In this section, we have investigated the distribution of quantifiers, articles/demonstratives, possessive pronouns and adjectives within noun phrases in the history of English. In section 2.1, we found that the distribution of quantifiers, which are classified into predeterminers, central determiners and postdeterminers, is basically the same in PE and early English. Based on the fact that their positions have been fixed throughout the history of English, it would follow that the determiner system as in Table 1 was already established in the OE period, at least for quantifiers.

Section 2.2 discussed the case of double determiners. We observed that the relative order between articles/demonstratives and possessive pronouns was free in $\mathrm{OE}$, but it was only possible for articles/demonstratives to precede possessive pronouns in ME and EModE, as shown in Tables 7, 8 and 9. In cases where they cooccur with adjectives within the same noun phrase, the situation of the relative word order among these three elements is as follows: (i) adjectives cannot precede articles/demonstratives, (ii) adjectives cannot precede possessive pronouns in the absence of articles/demonstratives, (iii) adjectives can precede possessive pronouns and vice versa, when articles/demonstratives precede both of them, and (iv) when possessive pronouns precede articles/demonstratives in $\mathrm{OE}$, adjectives cannot intervene between them. Then, the possible word order patterns of elements within noun phrases in early English can be summarized in (10).

(10) a. Art/Dem - (Adj) - N

b. Poss - (Adj) - N 


\section{c. Art/Dem - (Adj) - Poss - (Adj) - N \\ d. Poss - Art/Dem - (Adj) - N (only in the OE period)}

After reviewing previous studies in section 3 , we will provide a syntactic analysis of the word order patterns in (10) in section 4, arguing that the variety of word order patterns of elements within noun phrases is attributed to the unique behavior of possessive pronouns in early English, with the rest of the determiner system unchanged in the history of English. Concretely, the base-generated position of possessive pronouns was lower than that of articles/demonstratives in early English, but possessive pronouns have been grammaticalized and finally become a central determiner by PE. This would imply that the structure of noun phrases has been constant in the history of English with articles/demonstratives occupying the head of DP as central determiners, thus arguing against Yamamoto's (1989) and Osawa's (2000) view that the functional category D was absent in early English.

\section{Previous Studies on Noun Phrases in Early English}

Before discussing the structure of noun phrases and the determiner system in early English, let us review some previous studies on noun phrases in early English First of all, Fischer and Wurff (2006) summarize the determiner system and the positions of quantifiers in early English, as shown in Table 10.

\section{Table 10}

\begin{tabular}{|c|l|l|l|}
\hline Changes in: & \multicolumn{1}{|c|}{ Old English } & Middle English & Modern English \\
\hline $\begin{array}{l}\text { determiners: } \\
\text { system }\end{array}$ & $\begin{array}{l}\text { articles present } \\
\text { in embryo- } \\
\text { form, system } \\
\text { developing }\end{array}$ & $\begin{array}{l}\text { ariticles used } \\
\text { for presen- } \\
\text { tational and } \\
\text { referential } \\
\text { functions }\end{array}$ & $\begin{array}{l}\text { also in use in } \\
\text { predicative and } \\
\text { generic contexts }\end{array}$ \\
\hline double det. & present & rare & absent \\
\hline $\begin{array}{l}\text { quantifiers: } \\
\text { position of }\end{array}$ & relatively free & more restricted & fairly fixed \\
\hline
\end{tabular}

(Fischer and Wurff (2006: 111))

They observe that double determiners had been found until early ME but soon thereafter died out in common usage, because possessive pronouns came to be treated as central determiners. They also note that the positions of quantifiers were relatively free within noun phrases in $\mathrm{OE}$, and they grad- 
ually became fixed as time passed, citing the following examples in which each and any, which are classified as central determiners, occur before another central determiner.

(11) a. celc an hagelstan each a hailstone

b. ony the other eyght any the other eight

(HomU36(Nap45)51)

(Caxton's Preface,Vinaver,1967:cxii,6) (Fischer and Wurff (2006: 120-121)) However, their observations are incompatible with the results of the investigation in the previous section: the distribution of quantifiers in early English was basically the same as that in PE, and double determiners were still attested in EModE. Thus, Fischer and Wurff's observation summarized in Table 10 is not tenable, and it must be concluded that examples like (11) were extremely rare.

Second, focusing on the behavior of adjectives, Mitchell (1985) observes the possible word order patterns among adjectives, possessive pronouns and demonstratives within noun phrases in $\mathrm{OE}$, which are summarized in (12).
a. Poss - Dem - (Adj) - N
b. Dem - Poss - Adj - N
c. Poss - Adj - N
d. Dem - Adj - N
e. an/sum/adjective denoting quantity or number - Adj- $\mathrm{N}$

It should be noticed in (12) that the cooccurrence of demonstratives and possessive pronouns is possible, but adjectives do not precede other elements, as opposed to the observations by Carlson (1978), Lightfoot (1979) and Yamamoto (1989), which will be discussed below. Mitchell's observation, however, does not suffice to accommodate the results of the investigation in the previous section, in that it does not cover the order Art/DemAdj-Poss-N that was available from OE to EModE (see Table 8).

Third, Yamamoto (1989) observes that adjectives were free to occur before or after demonstratives and possessive pronouns in early English. According to her, the word order patterns shown in (2), which are repeated here as (13), were possible in early English, as shown in (14) (see Carlson (1978) and Lightfoot (1979) for similar observations).

(13) a. *good the king (cf. the good king)

b. *old my friends (cf. my old friends)

a. mid sele pan kinge

with good the king

'with the good king'

(Lawman-Lightfoot) 
b. sweet my child

(Love I ii 68)

(Yamamoto (1989: 3))

(15) a. Hie pa lærde se hera halga bisceop them then instructed that their holy bishop 'Then their holy bishop instructed them' (BlHom 201.24)

b. this his distemper he is in now

(Wives IV ii 28)

(16) a. Ne cwæð he no ðin sio winestre hond, ac ðin not said he no your that left hand but your sio swiðre that right "He did not say 'your left hand, but "your right""

(CP 389.20)

b. mid hire pcere yfelan sceonesse \& facne with her that evil suggestion treachery 'with her evil suggestion and treachery'

Yamamoto treats the examples in (16) differently from those in (14) and (15): while the adjectives, demonstratives and possessive pronouns occupy their base-generated positions in (14) and (15), the possessive pronouns in (16) are base-generated lower than the demonstratives and are then topicalized to yield the surface word order. According to her, examples like (14) and (15), which are disallowed in PE, were often observed in OE because the structure of noun phrases in early English was different from that in PE.

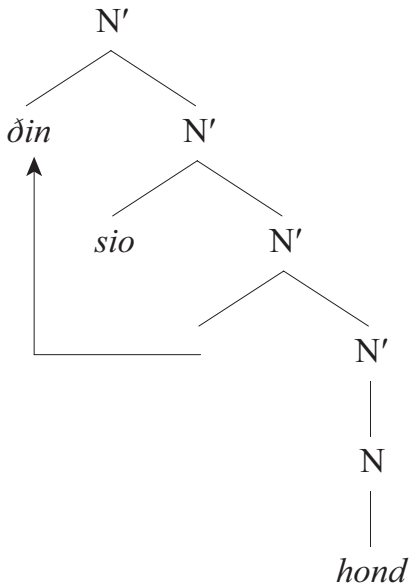

(ibid.: 5) 
Adopting the ideas of Fukui $(1986,1988),{ }^{7}$ Yamamoto assumes the structure of noun phrases in early English as in (17), where N projects up to the single-bar level and allows the iteration of that level with no specifier. In cases where possessive pronouns precede demonstratives, they are topicalized to adjoin to $\mathrm{N}^{\prime}$, as illustrated in (17). She also argues that in early English, demonstratives and possessive pronouns were not distinct from adjectives generated at the $\mathrm{N}^{\prime}$ level, and that the relative order of elements within noun phrases was determined by semantic and pragmatic factors. This is the reason why the examples in (14)-(16) were allowed in early English. According to her, the functional head D has emerged and the structure of noun phrases has become DP in the history of English, with the result that the word order of elements is fixed within noun phrases in PE.

In Table 6, it was observed that adjectives basically cannot be in the leftmost position when they cooccur with either demonstratives or possessive pronouns. This fact is incompatible with Yamamoto's observation that adjectives could freely precede demonstratives and possessive pronouns in early English. Moreover, her analysis predicts that elements within noun phrases are free to appear at the $\mathrm{N}^{\prime}$ level and their relative word order depends on semantics and pragmatics. However, it does not properly capture the distributional facts in Tables 7, 8 and 9: the pattern Poss-Art/Dem(Adj)-N died out much earlier than the pattern Art/Dem-(Adj)-Poss-(Adj)-N, and adjectives could only precede possessive pronouns in the presence of articles/demonstratives.

Fourth, Alexiadou (2004) discusses the development of possessive pronouns, adopting Cardinaletti's (1998) tripartite division of pronouns into clitic, weak and strong pronouns. She argues that possessive pronouns in PE are clitics whereas those in early English were either strong or weak adjectives, and that they are both base-generated in Spec-nP, giving the structure of noun phrases in (18).

(18) a. [TорP [DP [D' clitic $_{\mathrm{i}}\left[\mathrm{AgrP}\right.$ Agr $\left.\left.\left.\left[{ }_{\mathrm{nP}} t_{\mathrm{i}}\left[\mathrm{n}^{\prime} \mathrm{n} \mathrm{NP}\right]\right]\right]\right]\right]$

b. [Topp [DP Dem [D, D [AgrP weak ${ }_{\mathrm{j}}\left[\mathrm{Agr}^{\prime}\right.$ Agr $\left.\left.\left.\left.\left[\mathrm{np}_{\mathrm{j}} t_{\mathrm{j}}\left[\mathrm{n}^{\prime} \mathrm{n} \mathrm{NP}\right]\right]\right]\right]\right]\right]$

c. [Topp [DP Dem [D D [Agrp [Agr' Agr [np strong [n' $\mathrm{n} \mathrm{NP}]]]]]]]$

(cf. Alexiadou (2004: 35))

According to her, clitic possessive pronouns move to the head of DP, weak

${ }^{7}$ Fukui $(1986,1988)$ argues that lexical categories only project up to the single-bar level without closing off their projections whereas functional categories may project up to the double-bar level and have a specifier which closes off their projections. 
possessive pronouns move to Spec-AgrP and strong possessive pronouns remain in Spec-nP. She argues that weak possessive pronouns move to Spec-TopP when they cooccur with adjectives within the same noun phrase, because adjectives occupy Spec-AgrP, competing with weak possessive pronouns for the same position.

Alexiadou's analysis seems to have some problems in explaining the word order patterns in (10), which are repeated here as (19).
a. Art/Dem - (Adj) - N
b. Poss - (Adj) - N
c. Art/Dem - (Adj) - Poss - (Adj) - N
d. Poss - Art/Dem - (Adj) - N (only in the OE period)

First, according to her analysis, the order in (19d) is possible only when adjectives are present, but as many as 64 examples of the order Poss-Art/ Dem-N are attested in YCOE, as we saw in Table 7. Second, her analysis predicts that the order Art/Dem-Poss-Adj-N is never attested because weak possessive pronouns obligatorily move to Spec-TopP whenever adjectives are present within the same noun phrase, contrary to the results of the investigation in Table 8. Third, like Yamamoto (1989), her analysis would yield the impossible order Adj-Poss-N, if adjectives cooccur with strong possessive pronouns which remain in Spec-nP.

In summary, there is a consensus among the previous studies reviewed above that articles/demonstratives and possessive pronouns could cooccur in early English, but the relative word order among articles/demonstratives, possessive pronouns and adjectives is controversial, and no previous studies can properly capture all the possible word order patterns attested in the investigation in section 2. Moreover, it was pointed out that there are serious empirical problems with the generative analyses of noun phrases in early English proposed by Yamamoto (1989) and Alexiadou (2004).

In the next section, based on the conclusion in section 2 that the word order of elements within noun phrases in early English is basically the same as in PE except for possessive pronouns, I argue that the variety of the word order patterns shown in (10) is attributed to the unique behavior of possessive pronouns in early English. There has been no emergence of the functional category $\mathrm{D}$, nor change in the structure of noun phrases, in the history of English: the determiner system equivalent to that in PE was already established in $\mathrm{OE}$, except for possessive pronouns, which were grammaticalized into a central determiner during LModE. 
4. Explaining the Distribution of Elements within Noun Phrases

This section provides a syntactic analysis of the distribution of elements within noun phrases in the history of English. As observed in section 2, the distribution of quantifiers which are classified into predeterminers, central determiners and postdeterminers is basically the same in PE and early English, and the word order variations involving articles/ demonstratives, possessive pronouns and adjectives fall under the limited patterns shown in (10). I argue that the syntactic status of possessive pronouns in early English was different from that in PE, which made possible the cooccurrence of articles/demonstratives and possessive pronouns within the same noun phrase in early English. I also claim that possessive pronouns were grammaticalized into a central determiner during LModE, by examining the relevant data from The Corpus of Late Modern English Texts (henceforth, CLMET).

4.1. The Structure and Licensing of Noun Phrases

Before discussing the syntactic positions of elements within noun phrases, let us introduce the DP Hypothesis proposed by Abney (1987). He claims that the category of noun phrases is DP headed by the functional category D, which takes NP as its complement, as shown in (20).

(20)

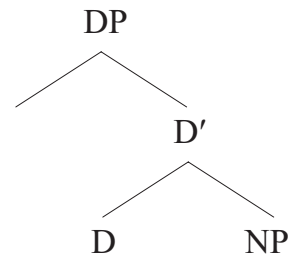

However, it is widely argued that there must be some functional projection(s) between DP and NP (see Carstens (2000), Bernstein (2001) and Brugé (2002) among others). Following Bernstein (2001), I assume the structure of noun phrases as in (21), where Num(ber)P is located between DP and NP. 
(21)

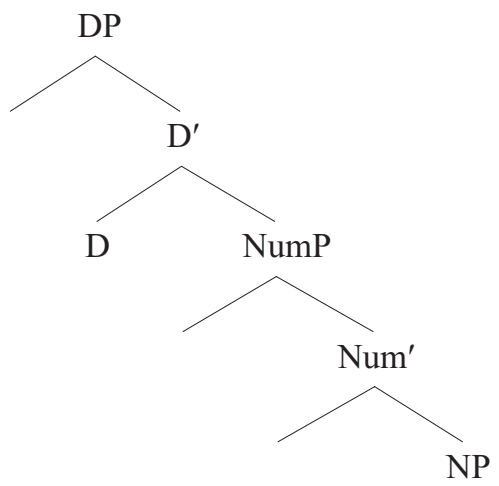

(cf. Bernstein (2001: 556))

Another important assumption adopted here is that definite noun phrases have the [+definite] feature in the head of DP and they are licensed by having definite material in the local domain of D. Formulating this idea in terms of feature checking, I propose the following licensing condition on definite noun phrases, where elements that can license them include the definite article, demonstratives and possessive pronouns.

(22) Definite noun phrases are licensed iff the [+definite] feature of D enters into a checking relation with its matching element(s) in a Spec-head and/or a head-head configuration.

This condition on definite noun phrases is reminiscent of Frisch's (1997) analysis of sentential negation, according to which NegP must be licensed by having a negative element in its head and/or its specifier position. Although he proposes the implementation of this idea in terms of Speas' (1994) Economy of Projection, his proposal can be recast by assuming that the $[+\mathrm{Neg}]$ feature of Neg must enter into a checking relation with its matching element(s). The checking of the $[+\mathrm{Neg}]$ feature is also established under a Spec-head and/or a head-head configuration: according to Frisch, NegP is licensed by having $n e$ in Neg in early ME, by having $n e$ in Neg and not in Spec-NegP in middle ME and by having not in Spec-NegP in late ME. ${ }^{8} \quad$ Note that in Frisch's analysis there is no prohibition on having both licensing positions in NegP filled in the transitional period when sentential negation was expressed by ne ... not. As we will see in the next section, the same seems to be true of definite noun phrases: the order PossArt/Dem-(Adj)-N illustrates the case where both the head and specifier posi-

${ }^{8}$ According to Roberts (1993) and Ishikawa (1995), not came to occupy the head of NegP during EModE. 
tions of DP are filled with definite elements.

4.2. The Positions of Elements within Noun Phrases

4.2.1. Quantifiers

Let us consider how quantifiers are positioned in the structure (21). We observed in section 2 that the distribution of quantifiers in early English is basically the same as in PE. First, the quantifiers classified as central determiners, namely every, any and some, are taken to occupy the head of DP, because they rarely cooccur with articles/demonstratives throughout the history of English.

Second, as for the quantifiers classified as predeterminers, namely all, both and half, they typically precede articles/demonstratives in PE and early English, so that their position must be somewhere to the left of articles/ demonstratives. Amano (2007) discusses two possible positions of predeterminers by citing the following examples.

(23) a. all the ideas: [DP all [DP $\left[\mathrm{D}^{\prime}[\mathrm{D}\right.$ the $[\mathrm{NP}$ ideas $\left.]]\right]$

[DP all [D' $[\mathrm{D}$ the] [NP ideas]]]

b. all John's ideas: [DP all [DP John [D' [D 's] [NP ideas]]]]

(Amano (2007: 28))

Along the lines of his analysis, I assume that predeterminers occupy SpecDP or are adjoined to DP; the latter option is necessary when another element occupies Spec-DP, as illustrated in (23b).

Third, quantifiers such as many, few and several as well as numerals are classified as postdeterminers, and they appear after central determiners in PE and early English. Since they are typically associated with the number of the entity denoted by the noun, it is natural to assume that they appear in the head of NumP. Summarizing the discussion of the three classes of quantifiers so far, the structure of noun phrases are schematized as in (24), which has been constant throughout the history of English.

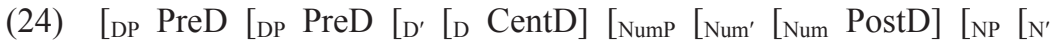
$\mathrm{N}][]][]]$

4.2.2. Articles/Demonstratives, Possessive Pronouns and Adjectives

Next, let us consider the distribution of articles/demonstratives, possessive pronouns and adjectives within noun phrases, beginning with the word order patterns in (10c, d) available only in early English.
a. Art/Dem - (Adj) - N
b. Poss - (Adj) - N
c. Art/Dem - (Adj) - Poss - (Adj) - N 


\section{d. Poss - Art/Dem - (Adj) - N (only in the OE period)}

I argue that the key difference between PE and early English is the syntactic status of possessive pronouns, which in turn allows the cooccurrence of articles/demonstratives and possessive pronouns in early English. This implies that the position of articles/demonstratives is the same in PE and early English: they occupy the head of DP. On the other hand, given the possibility of (10c), I assume that possessive pronouns are base-generated in a lower position than articles/demonstratives in early English: the relevant position is Spec-NumP because possessive pronouns typically precede postdeterminers occupying the head of NumP within the same noun phrase, as shown in Table 11, followed by examples from each corpus.

Table 11

\begin{tabular}{|c|c|c|c|}
\hline & Poss - PostD - N & PostD - Poss - N & Total \\
\hline YCOE & $209(93.72 \%)$ & $14(6.28 \%)$ & 223 \\
\hline PPCME2 & $120(99.17 \%)$ & $1(0.83 \%)$ & 121 \\
\hline PPCEME & $173(98.29 \%)$ & $3(1.71 \%)$ & 176 \\
\hline
\end{tabular}

a. heora twegen consulas their two consuls

(coorosiu,Or_2:5.49.19.950:02)

b. yure many wordis your many words

(CMBENRUL,19.668:m3)

c. their many Crimes

(BOETHPR-E3-P1,21.42:e3)

If the above arguments are on the right track, there will be two possible underlying structures of noun phrases that involve articles/demonstratives, possessive pronouns and adjectives, depending on whether adjectives are adjoined to NP or NumP, as shown in (26). ${ }^{9}$

${ }^{9}$ Evidence that adjectives in early English can be adjoined either to NP or NumP comes from examples like (i) where they precede postdeterminers.

(i) a. pam healican tyn bebodum those high ten commands

b. unsmerigne healfne cyse not-fatty half cheese

(colwstan2,æLet_3_[Wulfstan_2]:145.212:03)

c. the small two quarters

(colaece,Lch_II_[2]:65.2.6.3416:o2)

(STAT-1600-E2-H,IV,1026.14:e2)

The option of adjoining adjectives to NumP seems to have been available until EModE, yielding the order Art/Dem-Adj-Poss-N. However, adjectives can be adjoined only to NP in PE, because examples like (i) are ungrammatical. Therefore, it might be conjectured 


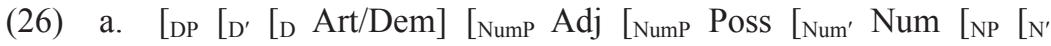
$\mathrm{N}][]]$ ] ] $]$

b. ${ }_{D \mathrm{DP}}\left[\mathrm{D}^{\prime}[\mathrm{D}\right.$ Art/Dem $]\left[_{\mathrm{NumP}}\right.$ Poss $\left[{ }_{\mathrm{Num}} \mathrm{Num}\left[\mathrm{NP}\right.\right.$ Adj $\left[\mathrm{NP}\left[\mathrm{N}^{\prime}\right.\right.$ $\mathrm{N}][]]]]]$

These structures immediately account for the order Art/Dem-(Adj)-Poss(Adj)-N in (10c), which had been available until the EModE period. Note that the condition (22) is satisfied in (26) because the [+definite] feature of $\mathrm{D}$ is checked under a head-head relation with articles/ demonstratives.

Turning now to the order Poss-Dem-(Adj)-N in (10d), suppose that possessive pronouns could optionally move to Spec-DP in OE, as shown in (27).

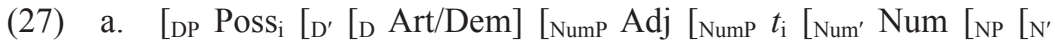
$\mathrm{N}][]]$ ]]]

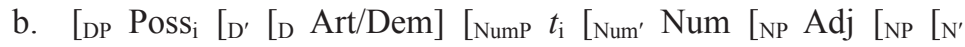
$\mathrm{N}][]]$ ]]]

This results in the checking of the [+definite] feature of $\mathrm{D}$, under both a Spec-head and a head-head relation; recall that there is no prohibition on having both licensing positions filled in the case of NegP (Frisch (1997))..$^{10}$ This movement analysis accounts for the order in (10d), as well as the fact that when possessive pronouns precede articles/demonstratives, adjectives cannot intervene between them. However, recall from section 2 that the relevant word order was lost in the ME period. This means that the movement of possessive pronouns to Spec-DP became impossible, which is argued to be closely related to their grammaticalization in the next section.

Finally, consider the word order patterns in $(10 \mathrm{a}, \mathrm{b})$. It was observed in Table 6 that adjectives typically follow articles/demonstratives and possessive pronouns when the latter two do not cooccur within the same noun phrase. The structures of $(10 a, b)$ are as in $(28 a, b)$, respectively.

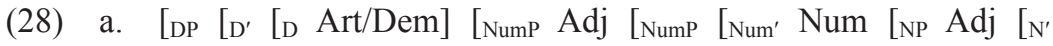
$\mathrm{N}][]][]]]$

that the change in the adjunction site of adjectives happened within noun phrases during LModE.

${ }^{10}$ This analysis assumes that possessive pronouns move to Spec-DP to check the [+definite] feature of D in (27). Given that the feature has already been checked by articles/ demonstratives, another possibility would be that possessive pronouns are topicalized to Spec-DP without checking the [+definite] feature of D, along the lines of Yamamoto (1989) (see section 3). 


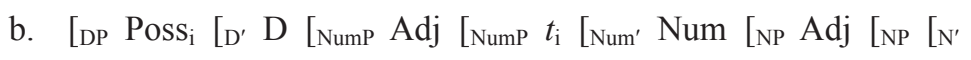
$\mathrm{N}][]][]]]$

It immediately follows from the structure (28a) that articles/demonstratives always precede adjectives, regardless of whether adjectives are adjoined to NP or NumP. There, articles/ demonstratives serve to check the [+definite] feature of $\mathrm{D}$ under a head-head relation. On the other hand, in (28b), possessive pronouns must raise to Spec-DP in order to enter into a checking relation with the [+definite] feature of $\mathrm{D}$ in the absence of other matching elements. Hence, the order Poss-Adj-N is derived, regardless of whether adjectives are adjoined to NP or NumP.

\subsection{The Grammaticalization of Possessive Pronouns}

This section attempts to clarify the syntactic status and the grammaticalization path of possessive pronouns in the history of English, which influenced their word order patterns within noun phrases after ME. I argue that the motivation for the grammaticalization of possessive pronouns is economy, in the sense of Gelderen (2004).

First of all, let us briefly review Gelderen's (2004) approach to grammaticalization. She argues that grammaticalization is driven by the two economy principles as shown in (29) and (30).

(29) Head Preference or Spec to Head Principle:

Be a head, rather than a phrase.

(Gelderen (2004: 11))

(30) Late Merge Principle:

Merge as late as possible.

(ibid.: 12)

Concerning the principle in (29), she presents plenty of examples where the position of elements has shifted from a specifier to a head within the same phrase in the history of English. One of such examples is the complementizer that. She argues that the complementizer that occupied Spec-CP in OE, by showing the example in (31).

(31) forðam wearð ylda bearnum undyrne cuð
therefore became to-elders to-children not-hidden known
gyddum geomore peet pe Grendel wan hwile
through-tales sadly that that Grendel fought while
wið Hropgar
against Hrothgar

'Therefore, all mankind found out in sad tidings that Grendel fought against Hrothgar.'

(Beowulf 149-151)

(ibid.: 89-90))

This example involves the two italicized elements in the CP domain: one 
corresponds to that and occupies Spec-CP, while the other is the particle pe and occupies the head of CP. Gelderen argues that the complementizer that first appeared in Spec-CP, but changed its position to the head of CP in late $\mathrm{OE}$ in accordance with the Spec to Head Principle, leading to the loss of examples like (31).

On the other hand, the principle (30) indicates that it is more economical to wait as long as possible before merging than to merge early and then move. Chomsky (2000, 2001a, 2001b) also shares the same insight as (30), calling it Merge over Move. Gelderen cites the well-known case of grammaticalization of modals as an example resulting from the change from a head to a higher head in accordance with the Late Merge Principle. According to her, the base-generated position of modals, which functioned as main verbs in $\mathrm{OE}$ and $\mathrm{ME}$, changed from $\mathrm{V}$ to $\mathrm{Asp}(\mathrm{ect})$, and later to $\mathrm{M}(\mathrm{ood}) .{ }^{11}$

With this in mind, let us consider the position and the grammaticalization path of possessive pronouns in the history of English. As we saw in the previous section, possessive pronouns are base-generated in Spec-NumP in OE, optionally moving to Spec-DP when they cooccur with articles/demonstratives, as shown in (32).

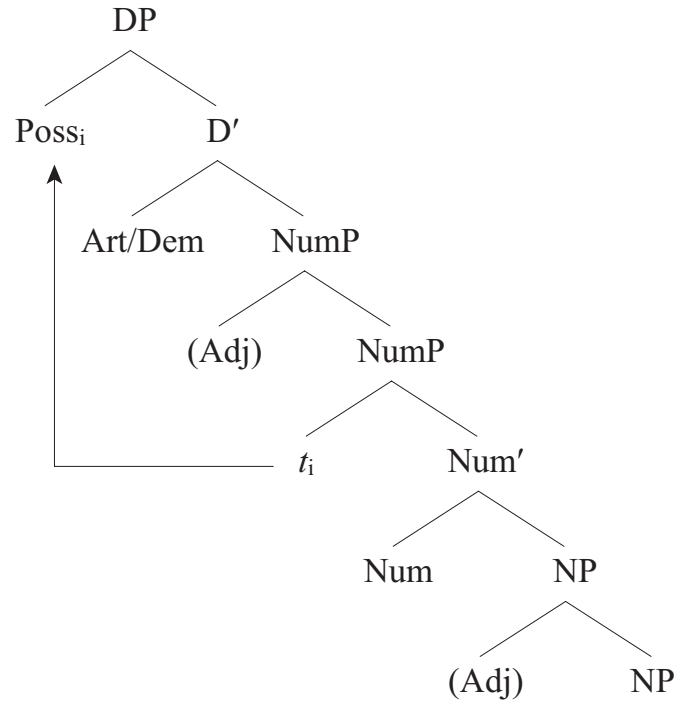

11 Gelderen amply presents examples of grammaticalization that have been driven by the Spec to Head Principle and the Late Merge Principle: personal pronouns, negatives, relatives and so on, for the former, and adverbs, perfect auxiliaries, progressive auxiliaries, and so on, for the latter. 
If possessive pronouns remain in situ, there are two possible word order patterns depending on the position of adjectives, namely Art/Dem-Adj-Poss-N and Art/Dem-Poss-Adj-N. If possessive pronouns move to Spec-DP, the resulting word order is Poss-Art/Dem-Adj-N. In all these word order patterns, the [+definite] feature of $\mathrm{D}$ is checked by articles/ demonstratives occupying the head of DP (as well as by possessive pronouns in the order Poss-Art/Dem-Adj-N). Note that possessive pronouns obligatorily move to Spec-DP in the absence of articles/demonstratives, because there are no other matching elements to check the [+definite] feature of D.

In accordance with the Spec to Head Principle, suppose that possessive pronouns became the head of NumP in ME, so their movement came to target the head of DP, which is the base-generated position of articles/demonstratives. Therefore, when articles/demonstratives appear in the head of DP, possessive pronouns cannot move there, as shown in (33). Note that even though the movement of possessive pronouns does not occur, the [+definite] feature of D is successfully checked by articles/demonstratives in the head of DP without the movement of possessive pronouns.

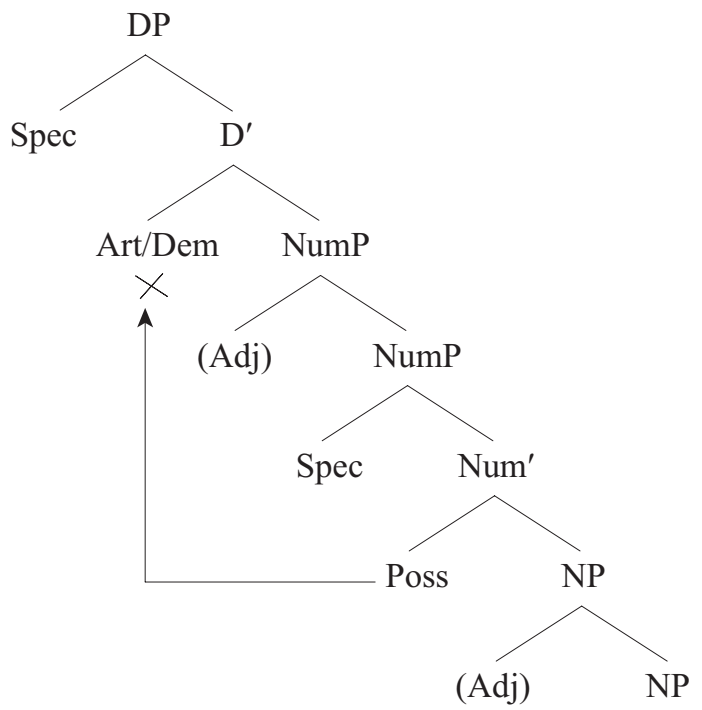

On the other hand, when articles/demonstratives do not appear in the head of DP, possessive pronouns obligatorily move there to check the [+definite] feature of D. This analysis can properly capture the results of the investigation summarized in Tables 7 and 9: the order Poss-Art/Dem-(Adj)-N was lost in ME, whereas the order Art/Dem-(Adj)-Poss-(Adj)-N was still attested in EModE. 
The obligatory movement of possessive pronouns to the head of DP in the absence of articles/demonstratives led to their further grammaticalization in accordance with the Late Merge Principle: they came to be directly merged in the head of DP, as shown in (34).

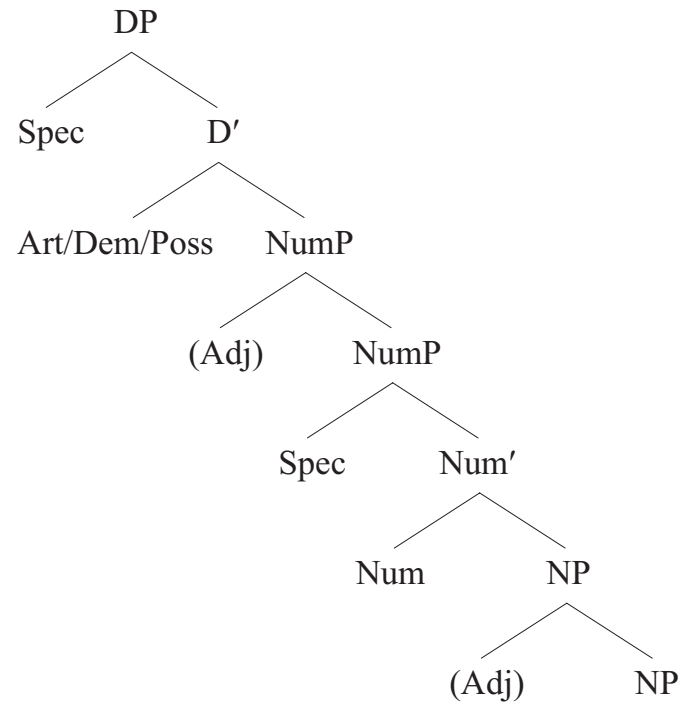

In (34), articles/demonstratives and possessive pronouns compete for the same position, the head of DP. This is why they cannot cooccur within the same noun phrase in PE. Their cooccurrence is still observed in PPCEME, so that the grammaticalization of possessive pronouns driven by the Late Merge Principle must have happened in the LModE period.

In order to confirm this, I have investigated the distribution of double determiners in LModE by using the CLMET. Together with the results of the investigation based on PPCEME, the first row in Table 12 represents the numbers of examples attested in the corpora, and the second row represents the numbers of double determiners per a hundred thousand words in each sub-period of ModE.

Table 12

\begin{tabular}{|c|c|c|c|c|c|c|}
\hline & $\begin{array}{c}\text { EModE1 } \\
\left(1500^{-}\right. \\
1570)\end{array}$ & $\begin{array}{c}\text { EModE2 } \\
\left(1570^{-}\right.\end{array}$ & $\begin{array}{c}\text { EModE3 } \\
(1640)\end{array}$ & $\begin{array}{c}\text { LModE1 } \\
\left(1710^{-}\right.\end{array}$ & $\begin{array}{c}\text { LModE2 } \\
\left(1780^{-}\right.\end{array}$ & $\begin{array}{c}\text { LModE3 } \\
\left(1850^{-}\right.\end{array}$ \\
& 63 & 58 & 50 & 57 & $1850)$ & $1920)$ \\
\hline Number & 63 & 97 & 47 \\
\hline$/ 100,000 w o r d s$ & 10.93 & 8.86 & 8.85 & 1.88 & 1.69 & 0.91 \\
\hline
\end{tabular}


Although the number of tokens of the relevant examples remains almost unchanged in ModE, there is a radical reduction in the frequency of double determiners in the transition from EModE3 to LModE1, and it gradually decreases during LModE. Therefore, it is plausible to conclude that the grammaticalization of possessive pronouns into a central determiner occupying the head of DP was completed during LModE.

To sum up, this section has discussed the grammaticalization of possessive pronouns in the history of English in the light of the two economy principles proposed by Gelderen (2004). The position of possessive pronouns changed from Spec-NumP to the head of NumP in ME, in accordance with the Spec to Head Principle. This made the order Poss-Art/Dem-(Adj)-N impossible, since possessives could no longer move to the head of DP in the presence of articles/demonstratives. Then during the LModE period, possessive pronouns were further grammaticalized and came to appear in the head of DP, leading to the loss of double determiners.

\section{Conclusion}

In this paper, I have discussed the distribution of quantifiers, articles/ demonstratives, possessive pronouns and adjectives within noun phrases in the history of English, arguing that the distributional differences between PE and early English are accounted for in terms of the unique behavior of possessive pronouns in early English. The possibility of the cooccurrence of articles/demonstratives and possessive pronouns in early English was shown to follow from their different syntactic positions: while articles/ demonstratives occupy the head of DP throughout the history of English, the base-generated position of possessive pronouns was Spec-NumP in $\mathrm{OE}$ and the head of NumP in ME and EModE. It was also argued that possessive pronouns were finally grammaticalized into a central determiner occupying the head of DP during LModE, thereby establishing the determiner system in PE.

\section{REFERENCES}

Abney, Steven P. (1987) The English Noun Phrase in Its Sentential Aspect, Doctoral dissertation, MIT.

Alexiadou, Artemis (2004) "On the Development of Possessive Determiners," Diachronic Clues to Synchronic Grammar, ed. by Eric Fuß and Carola Trips, 
31-58, John Benjamins, Amsterdam.

Allen, Cynthia L. (2003) "Deflexion and the Development of the Genitive in English," English Language and Linguistics 7, 1-28.

Amano, Masachiyo (2007) "On the Grammatical Reorganization of Both, All and Half," Exploring the Universe of Language: A Festschrift for Dr. Hirozo Nakano on the Occasion of His Seventieth Birthday, ed. by Masachiyo Amano, Kozo Kato, Makiyo Niwa, Ko-ichiro Hamasaki, Tomoyuki Tanaka, Yusaku Oteki, Kay Nakago and Eiko Mizuno, 21-33, Department of English Linguistics, Nagoya University, Nagoya.

Bernstein, Judy B. (2001) "The DP Hypothesis: Identifying Clausal Properties in the Nominal Domain," The Handbook of Contemporary Syntactic Theory, ed. by Mark Baltin and Chris Collins, 536-561, Blackwell Publishers, Oxford.

Brugé, Laura (2002) "The Position of Demonstratives in the Extended Nominal Projection," Functional Structure in DP and IP: The Cartography of Syntactic Structures Vol. 1, ed. by Guglielmo Cinque, 15-53, Oxford University Press, Oxford.

Cardinaletti, Anna (1998) "On the Deficient/Strong Opposition in Possessive System," Possessors, Predicates and Movement in the Determiner Phrase, ed. by Artemis Alexiadou and Chris Wilder, 17-54, John Benjamins, Amsterdam.

Carlson, Anita M. (1978) “A Diachronic Treatment of English Quantifiers," Lingua 46, 295-328.

Carstens, Vicki (2000) "Concord in Minimalist Theroy," Linguistic Inquiry 31, 319-355.

Chomsky, Noam (1995) The Minimalist Program, MIT Press, Cambridge, MA.

Chomsky, Noam (2000) "Minimalist Inquiries: The Framework," Step by Step: Essays on Minimalist Syntax in Honor of Howard Lasnik, ed. by Roger Martin, David Michaels and Juan Uriagereka, 89-155, MIT Press, Cambridge, MA.

Chomsky, Noam (2001) "Derivation by Phase," Ken Hale: A Life in Language, ed. by Michael Kenstowicz, 1-51, MIT Press, Cambridge, MA.

Chomsky, Noam (2004) "Beyond Explanatory Adequacy," Structures and Beyond: The Cartography of Syntactic Structures Vol. 3, ed. by Adriana Belletti, 104131, Oxford University Press, Oxford.

Chomsky, Noam (2007) "Approaching UG from Below," Interfaces + Recursion = Language?: Chomsky's Minimalism and the View from Syntax-Semantics, ed. by Uli Sauerland and Hans-Martin Gärtner, 1-29, Mouton de Gruyter, Berlin.

Chomsky, Noam (2008) “On Phases," Foundational Issues in Linguistic Theory: Essays in Honor of Jean-Roger Vergnaud, ed. by Robert Freidin, Carlos P. Otero and Maria Luisa Zubizarreta, 133-166, MIT Press, Cambridge, MA.

Fischer, Olga and Wim van der Wurff (2006) "Syntax," A History of the English Language, ed. by Richard Hogg and David Denison, 109-198, Cambridge University Press, Cambridge.

Frisch, Stefan (1997) "The Change in Negation in Middle English: A NEGP Licensing Account," Lingua 101, 21-64.

Fukui, Naoki (1986) A Theory of Category Projection and Its Applications, Doctoral 
dissertation, MIT.

Fukui, Naoki (1988) "Deriving the Differences Between English and Japanese: A Case Study in Parametric Syntax," English Linguistics 5, 249-270.

Gelderen, Elly van (2004) Grammaticalization as Economy, John Benjamins, Amsterdam.

Huddleston, Rodney and Geoffrey K. Pullum (2002) The Cambridge Grammar of the English Language, Cambridge University Press, Cambridge.

Ibaraki, Seishirou (2009) "The Distribution of Articles/Demonstratives, Possessive Pronouns and Adjectives within Noun Phrases in the History of English," Linguistics and Philology 28, 33-56.

Ishikawa, Kazuhisa (1995) "A History of Not: The Change from a Phase to a Head," English Linguistics 12, 197-221.

Lightfoot, David W. (1979) Principles of Diachronic Syntax, Cambridge University Press, Cambridge.

Matushansky, Ora (2002) Movement of Degree/Degree of Movement, Doctoral dissertation, MIT.

Mitchell, Bruce (1985) Old English Syntax, Vol. 1, Clarendon Press, Oxford.

Nakao, Toshio (1972) Eigoshi II (History of English II), Taishukan, Tokyo.

Osawa, Fuyo (2000) "The Historical Emergence of DP in English," English Linguistics 17, 51-79.

Quirk, Randolph, Sidney Greenbaum, Geoffrey Leech and Jan Svartvik (1985) A Comprehensive Grammar of the English Language, Longman, London and New York.

Roberts, Ian (1993) Verbs and Diachronic Syntax: A Comparative History of English and French, Kluwer Academic Publishers, Dordrecht.

Speas, Margaret (1994) "Null Argument in a Theory of Economy of Projection," University of Massachusetts Occasional Papers in Linguistics 17, 179-208.

Yamamoto, Keiko (1989) "The Historical Development of Determiners: A Parametric Approach," English Linguistics 6, 1-17.

\section{Corpora}

Kroch, Anthony and Ann Taylor (2000) Penn-Helsinki Parsed Corpus of Middle English Second edition (PPCME2), University of Pennsylvania, Pennsylvania.

Kroch, Anthony and Ann Taylor (2004) Penn-Helsinki Parsed Corpus of Early Modern English (PPCEME), University of Pennsylvania, Pennsylvania.

Smet, Hendrik De (2005) The Corpus of Late Modern English Texts (CLMET), University of Leuven, Belgium.

Taylor, Ann, Anthony Warner, Susan Pintzuk and Frank Beths (2003) The YorkToronto-Helsinki Parsed Corpus of Old English Prose (YCOE), University of York, Heslington.

The Collins Wordbanks Online (Collins) 


\section{Dictionary}

The Oxford Dictionary of the English Language (OED) (2nd ed.).

[received September 19 2008, revised and accepted January 12 2009]

Department of English Linguistics

Graduate School of Letters

Nagoya University

Furo-cho Chikusa-ku, Nagoya-shi

Aichi 464-8601

e-mail: ibarakiseishirou@gmail.com 